\title{
International Coordination and National Institutional Facilitating Mechanisms for Financial Technology Development, for the Sustainable Development Support
}

\author{
Viktoriya Razletovskaia* \\ Moscow State Institute of International Relations (MGIMO University), 76, Vernadskogo Avenue, \\ 119454 Moscow, Russia
}

\begin{abstract}
The Fintech, as the progress in technology, transforms the financial and investment landscape, creating both opportunities and challenges for all participants, risks to the stability and integrity of the financial system. The dematerialization of payments introduces new participants and new products to the market, including non-financial entities. At the next stage of the Fintech development, the importance of artificial intelligence and neurotechnology increases. As the Fintech, the artificial intelligence and the neurotechnology cross national and international regulatory boundaries, the effective cross-sectoral and crossdomain coordination and the mixed financing for global financial investment strategies are critical both domestically and internationally. The particular importance gains the possibilities of resource-maneuvering in global investment strategies, and mechanisms - interoperability coordination of various infrastructures, digital, financial, telecommunications, IT, government regulation, international cooperation. Due to the variety of such models, it is required to identify trends and promising areas of international coordination of fintech development [9]. What are the factors drawing the development back? What new models of national and international coordination of these technologies are most effective for achieving sustainable development goals?
\end{abstract}

\section{Introduction}

The role and influence of artificial intelligence and neurotechnology technologies on the Fintech grows annually. With the dematerialization of payments and digitalization of the banking sector, the introduction of biometrics and other technologies, the merger of these areas will only increase. The Fintech has stimulated the emergence of new products and services, ranging from payments to financing, asset management, insurance and financial consulting. Today, the following areas of application of artificial intelligence and neurotechnologies in finance and investments are most developed: credit assessment and

\footnotetext{
* Corresponding author: viktoriya777.vlasova@yandex.ru
} 
risk assessment, forecasting, proposing new products, chat bots, voice systems for processing client requests, predictive models of neuroeconomics, development of communication systems bypassing spoken and written speech, creation of brain-computer neurointerfaces, distributed ledger technologies, security, planning efficiency and investment management, personalization and targeting. The integration of new financial solutions allows to change the structure of consumption, reduce the costs of certain functionality (processing customer bases, loyalty programs, etc.), increase the efficiency and quality of business processes (targeting the target audience, scoring, etc.), as well as significantly affect sustainability development of core business, etc. The global financial technology market is one of the fastest growing in the world. The number of users of financial technologies in the world, according to expert estimates, is growing annually by $15-20 \%$, which is actively promoted by the Internet connectivity worldwide [7]. But the Fintech market is difficult for a comprehensive assessment due to its strong diversification and unavailability of data in multiple spheres.

The Fintech, artificial intelligence and neurotechnology cross national and international regulatory boundaries and aggravate traditional risks to financial stability and sustainable development displacing traditional market players and traditional business models. In addition to the traditional risks associated with underlying products and institutions, the Fintech can aggravate operational risks, as well as the data privacy and consumer protection risks. Ethical issues are reaching the new level and affect basic human rights and almost all aspects of our life. Advances in technology are changing existing institutional arrangements and rules, amending national development infrastructure and complicating international relations, given the inherent cross-border nature of many innovations.

The topic of financial stability mechanisms is widely discussed and regulated at the national and international levels. The 17 th sustainable development goal, confirmed in the $\mathrm{UN}$ resolution, is to strengthen means of implementation, primarily financial, and revitalize the Global Partnership for Sustainable Development. The goals and objectives set out in the Agenda presuppose the availability of funds necessary for their implementation and ensuring financial stability. The topics of financing technology development, ensuring financial stability and issues of ethics and global cooperation in the fields of Fintech, artificial intelligence and neurotechnology received a wide international discussion at the platforms of international organizations under the auspices of the UN. In this regard, the formation of institutional models and mechanisms for national and international coordination of fintech development is one of the priorities and urgent tasks of ensuring the goals and objectives of sustainable development.

\section{Methods}

Based on the combination of analysis of international organizations' operation in the field of the Fintech, artificial intelligence and neurotechnology, the study of publicly available documents of national legislation, international organizations, this paper describes the development trends of national and international institutional mechanisms for coordinating the Fintech development, and the segregation of duties between national bodies and international organizations, the organization of the main functions of supervisory bodies in the field of Fintech; and domestic and international coordination of fintech matters. Although the main purpose of this article is to describe the number of approaches to the institutionalization of national and international coordination used in individual countries and at the international level, to identify trends and prospects for their development, the article defines the relationship how the institutional format of coordination itself influences the process and coordination results. 


\section{Results and Discussion}

The main trends in the development of institutionalization of national models for coordinating the Fintech development. Fintech responsibilities are usually split between the traditional government and regulatory structures in finance, banking and the securities market. National Ministries of Finance and the Central Bank are taking an active interest in this area, leading high-level policy coordination, policy formulation and legislation development. For example, the French Ministry of Economy and Finance has spearheaded the development of a new French regime for crypto assets. The US Treasury Department has published a Financial Innovation Review containing policy advice for federal and state financial regulators and legislative proposals for the US Congress. The UK Treasury launched its Fintech sector development strategy, which included a series of statements from both regulators and government, including the task force in crypto assets, a new Fintech bridge and legislative pilot projects. The Ministry of Finance of Russia has developed a law on cryptocurrencies. The Bank of Russia not only acts as a mega-regulator, but also acts as an initiator and platform for the development of fintech projects. With his participation, a number of projects of national importance have already been implemented (Unified Biometric System, Faster Payment System, etc.

At the level of traditional regulators, fintech subdivisions with various functionalities are created, and expert groups from industry unions and the scientific sphere are formed to solve individual problems (Ministry of Finance of France, HM Treasury, the Central Bank of Russia, Ministry of Finance of Russia, etc.) Creation of new specialized agencies is practically does not happen, the functionality and responsibilities are redistributed between the existing departments of traditional structures. Supervisory functions are also carried out within the framework of traditional banking regulation (France, Great Britain) or sectoral supervision by industry, banking regulation, insurance and the securities market (Kenya, Hong Kong, USA, Emirates), or a unified supervisory authority (Japan, Malta, Russia, free economic zones Dubai and Abu Dhabi, Singapore, Switzerland) [1].

Law enforcement agencies also formally and closely cooperate with financial regulators on the Fintech issues in relation to fraud, money laundering, terrorist financing and other financial crimes. Other ministries, such as industry, technology and telecommunications, are less involved in the Fintech. The application of inter-agency approach to the Fintech (with the involvement of relevant ministries and departments) could help strengthen internal coordination and the strategic approach to its development. Countries differ in the emphasis placed on the Fintech development stimulation rather than regulating it. Some regulators prioritize traditional prudential targets. Others give more weight to innovation, inclusiveness, competition and development. Countries generally have not established fintech development structures to coordinate competition, fraud, technology and security issues outside of the main financial regulators. [2].

The coordination between different branches of government and regulators (both financial and non-financial) is required in the Fintech, which often creates new complexities due to new firms, products and activities outside the current regulatory perimeter. Considering the trade-offs between multiple policy objectives, such coordination is likely to be more complex than the coordination among financial authorities. A government-level coordination approach can be most effective for aligning strategic priorities while avoiding duplication or differences in regulations, especially if regulatory frameworks and institutional arrangements need to be adapted to facilitate the release of new products, activities and intermediaries. Interoperability is a prime example of the need 
for a holistic government approach to creating a conducive political environment for the Fintech. Interoperability stands out as a critical component in creating the foundation of the fintech ecosystem, and achieving it requires the coordination of several underlying infrastructures (e.g. telecommunications) as well as digital and financial infrastructures (such as broadband internet, bio- and neurotechnology, etc.)

In fact, further, instead of the Fintech development, the issue of regulating a unified technology of equivalent to the exchange of energy and information will arise.

Institutional national coordination models are determined by the Fintech development level and the strategic objectives and goals of its prospects.

Countries are taking different approaches to ensure the future international competitiveness of the Fintech and integration into the global agenda. For example, Hong Kong, Singapore, Dubai and Abu-Dhabi hold annual international Fintech exhibitions, pursue the coordinated and consistent policy to promote the brand at the global level and in the regions as a whole as global technological fintech hubs in Asia and the Arab world. [1]. Switzerland actively conducts international scientific training programs and develops education in this area, issues guidelines, methodological recommendations, etc. which are actively used by national authorities of various countries and international organizations. Among others, Japan for the purpose of cooperation between the Japanese financial market and international organizations, has headed the FSB (Financial Stability Board, chief regulator) standing committee. USA and Great Britain demonstrate an integrated approach to ensuring the international competitiveness of the Fintech. The consistent policy can be traced from the education system, the development of science and licensing, the creation of conditions for the development of start-ups, the creation of an ecosystem, the stimulation and regulation of foreign trade to the active work on outreach work at the global level and work in international organizations on legal regulation (regulatory sandboxes) and setting standards. China attracts technologies and scientists from all over the world, conducts active expansion, actively promotes its brands and technologies in the Fintech to third countries, while pursuing the protective policy to protect its market.

National priorities largely determine the formation of an international model for the Fintech development coordination. International Fintech coordination mechanisms are being formed, both bilateral and multilateral. Several countries have signed bilateral memoranda of understanding and letters of intent aimed at sharing information on emerging issues, including the Fintech. Moreover, there are examples of tighter Fintech-oriented coordination. For example, there is a recent initiative between Singapore and Hong Kong that explores the link between the Hong Kong Special Administrative Region's Distributed Trade Finance Accounting Technology platform and the similar platform in Singapore that allows banks in one jurisdiction to transact with banks in another and avoid fraudulent and multiple transactions). [1].

Currently, an example of global coordination is the Global Financial Innovation Network (GFIN), which brings together international regulators from over 50 jurisdictions (and observers from 17 countries) to discuss frameworks, practices and new ideas in the Fintech, including regulatory sandboxes. Great Britain was the driving force behind the creation of the GFIN. The GFIN builds on many of the existing agreements between executives and financial sector institutions. The GFIN is a collaborative policy and knowledge-sharing initiative to advance areas such as financial integrity; consumer welfare and protection; financial availability; competition; and financial stability through innovation in financial services, sharing experiences, working together on emerging policy issues and promoting responsible cross-border experimentation of new ideas [8].

Most, if not all, national financial authorities have some degree of involvement in the financial sector standard setting bodies. In the normal course of business, the Fintech issues 
are discussed and, when deemed appropriate, working groups are formed to address specific issues. For example, the Basel Committee on Banking Supervision (BCBS) Supervision and Implementation Group has created a FinTech Task Force. Examples of recent work by BCBS include the publication of sound practice on the implications of Fintech development for banks and regulatory authorities and an agreement to publish a discussion paper on the prudential regime of crypto assets. The International Organization of Securities Commissions has created a Fintech network and an IPO network. In May 2019, the organization has published an advisory report on crypto asset trading platforms. In October 2018, the guidelines and glossary were amended to clearly clarify that the guidelines apply in the case of financial activities related to virtual assets. One area of the potential sustained value for Fintech is the collaboration between financial regulators. The JFSA (Japan's chief financial regulator supervising the securities and investment markets) currently chairs the Standing Committee for the Supervision and Cooperation of the Financial Stability Board (FSB). The financial innovation network FSB actively discusses the stability of Fintech and regulatory aspects, sets applicable standards. A number of tasks in the field of Fintech and new technologies, mechanisms for financing sustainable development goals are considered at the site of the International Organization for Economic Cooperation and Development OECD. For example, as part of the development of mechanisms for promoting technology development for sustainable development, a working group has been formed and a project on blended financing of technology development until 2022 is being implemented, the Global Blockchain Policy Forum 2020 and other initiatives are being held.

The prospects for development of institutional models for the Fintech coordination should be considered along with the international infrastructure for the development of artificial intelligence and neurotechnologies.

International neurotechnology coordination trends indicate that no country or project for the study of brain functioning alone has the combined set of intellectual, technological, financial and human resources required for successful solution the problem of brain research. Since 2001, the resource has emerged that systematically analyzes the development of national health systems in the diagnostics and treatment of mental and neurological disorders: The World Health Organization has begun to regularly issue background information on the availability of mental health services and resources (financial appropriations, human resources, specialised mental health institutions, etc.) in the Mental Health Atlas series. Subsequently, other international organizations noted the importance of the development of neurosciences. The UN General Assembly in 2015 included mental health in the global Sustainable Development Goals, the World Economic Forum singled out the group of global tasks "Neurosciences" and established the Global Future Council on Technology for Mental Health. Individual countries have begun to support neuroscience and technology through Big Science Initiatives - large-scale research projects designed to significantly accelerate scientific progress. Due to the complementary nature of projects and the need to standardize the large amount of data generated within their framework, countries are seeking cooperation. Therefore, a coordinating international organization, the International Brain Initiative, was established, which included all existing national initiatives. Japan has also set up Brain / MINDS Beyond to cooperate with other countries and projects. [3]. Another important factor is the global nature of projects in terms of interaction with the global research community [10]. This policy is based on the belief that achieving a global breakthrough in the field of neurosciences and neurotechnologies is possible only with high-quality international 
cooperation. International conferences identify directions and areas of research and interaction where international coordination is especially important and likely to yield high results - if the specific benefits of individual brain research projects will be strengthened and the standardization will be implemented. [4]

International of artificial intelligence coordination trends indicate the absence of multilateral international treaties - conventions adopted at the level of the United Nations Organization, which would fix the general provisions for this sphere. Only a few documents have been adopted that contribute to the formation of international legal regulation foundations of in the field of artificial intelligence that serve guidelines, i.e. there is the legal regulation in the form of "soft law". Among such documents is the Okinawa Charter on Global Information Society dated July 22, 2000, which was signed by representatives of the eight leading world powers - the Big Eight (G8), which included Russia at that moment, and proclaiming the need to form the regulatory framework that promotes the cooperation on optimizing global networks and narrowing the digital gap. OECD Council Recommendation on Artificial Intelligence dated May 22, 2019 as the first intergovernmental standard on artificial intelligence. This document contains five principles and five recommendations for national governments and provides general recommendations. There is a transition from basic principles to the harmonization of general structural and descriptive model of artificial intelligence systems. Leading companies in the development of products based on artificial intelligence technologies seek to influence the processes of creating the rule of law, as a result of which one can observe "competition for leadership in promoting the image of artificial intelligence. The G20 Ministerial Statement on Trade and Digital Economy dated June 9, 2019, in which the principles of the development of artificial intelligence, taken from the previous document, were approved on behalf of the contributing countries of the so-called G20 (G20) - The Organization for Economic Co-operation and Development Artificial Intelligence Guidelines (as an attachment to the statement) [5]. Among G20 contributing countries are: Russia, USA, China, Germany, France, Italy, Great Britain, Australia, Canada, Japan, etc. The text of this document contains, among other things, items on: - joint work to create a sustainable and innovative global society (item 6); - the development and implementation of digital policies that can maximize benefits and minimize the problems associated with the development of the digital economy, taking into account special attention to developing countries and disadvantaged groups of the population (paragraph 7); - the need to build a digital society based on trust between all stakeholders, including governments, civil society, international organizations, academics and business, through the exchange of common values and principles, including equality, fairness, transparency and accountability, taking into account the global economy (paragraph 11); - recognizing the need for anthropocentricity in the development of artificial intelligence and taking into account the risks of new social problems, including changes in the labor market (paragraph 19); - the need to continue to promote the protection of confidentiality and personal data and the recognition of the need to promote the capacity building of artificial intelligence (paragraph 20). $\{2\}$ International Standards Organizations (ISO), the International Electrotechnical Commission (IEC) and the International Telecommunication Union (ITU) play an active role in the standardization of artificial intelligence. These organizations are recognized by all countries and, accordingly, have the authority to issue international standards, their activities are closely related and coordinated, including through the joint development of guidelines that address various aspects of conformity assessment activities. Although 
international standards are developed on the basis of consensus and voluntary recognition of the requirements set forth in them, in practice, compliance of products with these standards is necessary, since it serves as a criterion for competitiveness and admission to the international market. Currently, for all countries, it is a prerequisite to test complex products for their compliance with the requirements of technical guidelines regarding safety, threat to human life and health or the environment before products are released for sale. The largest of the above organizations is the International Organization for Standardization, of which 164 states are members, including the Russian Federation. ISO technical standards, containing the advanced scientific and technical experience of various countries, are aimed at ensuring the uniformity of requirements for products in the international exchange of goods, including the interchangeability of components, uniform test methods and product quality assessment. In 2017, a technical committee on artificial intelligence (ISO / IEC JTC 1/SC 42 Artificial intelligence) was established within the ISO structure. Thirty states are full members of the technical committee, and another 14 countries act as observers. International organizations are increasingly raising issues related to the discussion of draft international treaties related to the regulation of artificial intelligence. Constant work in this direction is being carried out, for example, by UNESCO, the UN specialized agency for education, science and culture. Such an event was the 40th session of the General Conference of UNESCO, at which a commitment was made to develop ethical standards in the development of artificial intelligence. Participants in the UNESCO Global Conference on Artificial Intelligence Call for Legal Management of Artificial Intelligence Experts selected by UNESCO will be responsible for preparing the preliminary text of an international normative document on the ethics of artificial intelligence. Two intergovernmental meetings are planned for 2021 to finalize ethical standards based on fundamental human rights [6]. The main areas of further discussion on the development of legal regulation of artificial intelligence are: concretization of the conceptual framework, ethics and human rights in connection with the spread of artificial intelligence in society, observance of public interests and the methodology for measuring various parameters and characteristics of artificial intelligence systems.

\section{Conclusions}

1. As the Fintech tends to cross regulatory boundaries, effective coordination is critical both domestically and internationally [9]. National and international coordination of the Fintech development takes various forms.

2. The national level coordination is usually carried out using existing top-level structures; when the Fintech issues arise, they are referred to the subcommittee or result in the creation of a task force to develop proposals. The national institutional model for coordinating the Fintech development is determined by the specifics and the technology growing point in a particular jurisdiction

3. In the perspective, with the great influence and spread of artificial intelligence and neurotechnologies in the Fintech, the intersectoral coordination, the interoperability and the inter-sphere interaction will be of particular importance at the next stage of its national level development. Currently, these mechanisms are practically absent or fragmentary, inconsistent, formal and unfinalized.

4. Institutional national coordination models are determined by the Fintech development level and the strategic objectives and goals of its prospects. In order to ensure the implementation of national and international competitiveness and security tasks, it is 
especially important to understand the general characteristics of geopolitical changes in the development of the Fintech, artificial intelligence and neurotechnologies, to determine the factors and conditions that affect the specifics of processes and the organization of the international relations system in this sphere.

5. International coordination mechanisms range from bilateral agreements and initiatives (such as memorandums of understanding on the Fintech) to multilateral coordinated international bodies to the setting of standards. It is used as a decentralized model of coordination, based on common rules, criteria and recommendations for decisionmaking at the national level for the contributing countries, as well as a centralized collective coordination model within which the contributing countries delegate certain powers to a supranational body - an international organization.

6. At this international cooperation stage of in the field of regulation of Fintech, artificial intelligence and neurotechnology, international agreements that are not binding are preferable. This indicates an increasing level of international competition and protectionism. Mutually beneficial intersection points for international regulation in the process of identifying in international discussion forums.

7. The nonuniformity and inconsistency of intersectoral coordination mechanisms for the development of Fintech, artificial intelligence and neurotechnologies are noted at the international level. So, with the increased influence of artificial intelligence and neurotechnologies on Fintech, the number of countries through international organizations have been developed and implemented standards, regulatory sandboxes for the Fintech, while in the field of artificial intelligence development only the first intergovernmental standard is adopted serving as guidelines, the transition from basic principles to agree on the general structure and descriptive model of artificial intelligence systems emerged, and in the field of neurotechnology at the international level of symposia and conferences under the auspices of international organizations, directions of international cooperation and coordination are determined; the development is monitored at the international organization level. All this widens the gaps in sectoral development at the international level, perpetuates inequality between countries in the development of fintech. It is required to develop coordinated approaches to the development of new Fintech technology using artificial intelligence (definitions for global level regulations, which standards and ethical norms shall be subject to control, which specific quantitative guidelines for the Fintech development should be observed for the sustainable development, which issues require joint ongoing consultations and agreements, the organization of monitoring at the international level, etc.) the self-isolation of countries, the escalation of conflicts, the closure of vertical borders, the limitation of cooperation, etc.

8. In the context of unstable economic situation, crises and the pandemic, intermediate country models of institutionalizing international coordination in the Fintech development, taking into account national specifics and interests, will most likely and effectively be used. For example, the creation of coalitions and joint projects in international organizations on national priorities for the Fintech development, the initiation of international cooperation and coordination of efforts on individual priorities and organizations according to the stages of national Fintech development, inter-sphere and intersectoral coordination of coalitions at the international level. In order to develop such coordination mechanisms, the Fintech development strategy should be clearly regulated, considering intersectoral coordination at the national level. Based on such strategy stages, the phased coordination mechanism at the international level has been developed. 
9. In order to ensure the holistic approach to regulation and development of Fintech, artificial intelligence and neurotechnology, and thus to build confidence in the financial system, the cooperation between various national and international bodies and good strategies for ensuring international competitiveness and leadership at the national level shall be the key to.

\section{References}

1. Charles Taylor, Christopher Wilson, Eija Holttinen, and Anastasiia Morozova, Institutional arrangements for Fintech regulation and supervisio (2019)

2. Douglas W. Arner, Jànos Barberis, Ross P. Buckley, Northwestern Journal of International Law and Busines, October (2016)

3. I.G. Dezhina. Technologies for recovery and expansion of human brain resources: Public analytical report (2020)

4. Z. Josh Huang, Liqun Luo, Science, 6256, 42 (2015)

5. G20 Ministerial Statement on Trade and Digital Economy (2019), https://www.mofa.go.jp/

6. General Director of UNESCO, Preliminary report on the first draft of the Recommendation on the Ethics of Artificial Intelligence

7. Fintech: The Experience so Far. International Monetary Fund Electronic copies of IMF Policy (2019), http://www.imf.org/

8. Global Financial Innovation Network. GFIN cross-border testing report 2020, GFIN cross-border testing work stream (2020)

9. I. Stepnov, J. Kovalchuk, E. Gorchakova, Studies on Russian Economic Development, 30(3), 346 (2019)

10. P.I. Kasatkin, J.A. Kovalchuk, I.M. Stepnov, Voprosy Ekonomiki, 12, 123 (2019) 